\title{
BMJ Open Economic costs of automated and continuous ambulatory peritoneal dialysis in Taiwan: a combined survey and retrospective cohort analysis
}

\author{
Chao-Hsiun Tang, ${ }^{1}$ Yu-Ting Wu, ${ }^{1,2}$ Siao-Yuan Huang, ${ }^{1}$ Hsi-Hsien Chen, ${ }^{3,4}$ \\ Ming-Ju Wu, ${ }^{5}$ Bang-Gee Hsu, ${ }^{6}$ Jer-Chia Tsai, ${ }^{7}$ Tso-Hsiao Chen, ${ }^{3,8}$ Yuh-Mou Sue ${ }^{3,8}$
}

To cite: Tang C-H, Wu Y-T, Huang S-Y, et al. Economic costs of automated and continuous ambulatory peritoneal dialysis in Taiwan: a combined survey and retrospective cohort analysis. BMJ Open 2017;7:e015067. doi:10.1136/bmjopen-2016015067

- Prepublication history and additional material is available. To view please visit the journal (http://dx.doi.org/ 10.1136/bmjopen-2016015067).

C-HT, Y-TW contributed equally to this work.

Received 10 November 2016 Revised 5 January 2017 Accepted 16 February 2017

CrossMark

For numbered affiliations see end of article.

Correspondence to Dr Yuh-Mou Sue; sueym@tmu.edu.tw

\section{ABSTRACT}

Objectives: Taiwan succeeded in raising the proportion of peritoneal dialysis (PD) usage after the National Health Insurance (NHI) payment scheme introduced financial incentives in 2005. This study aims to compare the economic costs between automated PD (APD) and continuous ambulatory PD (CAPD) modalities from a societal perspective.

Design and setting: A retrospective cohort of patients receiving PD from the NHI Research Database was identified during 2004-2011. The 1:1 propensity score matched 1749 APD patients and 1749 CAPD patients who were analysed on their NHI-financed medical costs and utilisation. A multicentre study by face-to-face interviews on 117 APD and 129 CAPD patients from five hospitals located in four regions of Taiwan was further carried out to collect data on their out-of-pocket payments, productivity losses and quality of life with EuroQol-5D-5L.

Outcome measures: The NHI-financed medical costs, out-of-pocket payments and productivity losses of APD and CAPD patients.

Results: The total NHI-financed medical costs per patient-year after 5 years of follow-up were significantly higher with APD than CAPD (US\$23 005 vs US $\$ 19237 ; p<0.01)$. In terms of dialysis-related costs, APD had higher costs resulting from the use of APD machines (US\$795) and APD sets (US\$2913). Significantly lower productivity losses were found with APD (US\$2619) than CAPD (US\$6443), but the out-of-pocket payments were not significantly different. The differences in NHI-financed medical costs and productivity losses between APD and CAPD remained robust in the bootstrap analysis. The total economic costs of APD (US\$30 401) were similar to those of CAPD (US\$29 939), even after bootstrap analysis (APD, US\$28 399; CAPD, US\$27 960). No discernable differences were found in the results of mortality and quality of life between the APD and CAPD patients.

Conclusions: APD had higher annual dialysis-related costs and lower annual productivity losses than CAPD, which made the economic costs of APD very close to those of CAPD in Taiwan.

\section{Strengths and limitations of this study}

- This is the first study to evaluate the overall economic costs of automated peritoneal dialysis (APD) and continuous ambulatory peritoneal dialysis (CAPD) modalities.

- This study comprises a retrospective cohort of patients receiving APD and CAPD from the National Health Insurance Research Database and a multicentre study by face-to-face interviews of APD and CAPD patients.

- The information about out-of-pocket payments and productivity losses collected from patient interviews, which were rarely assessed in previous studies, adds important economic data to the overall evaluation of the costs associated with patients undergoing APD and CAPD.

- The unidentified laboratory data from the database and other potential confounding factors such as patient preference, self-care ability and physician selection are drawbacks of this study.

- Productivity losses related to presentism (impaired productivity or reduced effectiveness at work associated with APD or CAPD) are not included in this study.

\section{INTRODUCTION}

Given that both the incidence and prevalence rates of end-stage renal disease (ESRD) in Taiwan are among the highest in the world, this particular disease has become an increasing burden on the Taiwan National Health Insurance (NHI) system's finances; indeed, by 2011, the cost of dialysis accounted for an astonishing $7.2 \%$ of the total annual NHI expenditure. ${ }^{12}$ In an attempt to contain the total costs of dialysis, in addition to applying a blanket budget cap on dialysis expenditure, a series of strategies were implemented by the NHI administrators to change the incentives relating to the choices of dialysis modalities.

Since peritoneal dialysis (PD) has an allcause mortality rate similar to that of 
haemodialysis (HD), but with lower medical costs, ${ }^{3-6}$ from 2005 onwards administrators within the Taiwan NHI have been actively promoting the use of PD, including automated PD (APD) and continuous ambulatory PD (CAPD), as a viable alternative treatment for dialysis. This is being achieved by a reduction in reimbursements for $\mathrm{HD}$ and a corresponding increase in those for PD, as well as the NHI payment scheme covering the APD machine costs. As a result, the use of PD in Taiwan has been gradually increasing, from $6.5 \%$ in 2003 to $8.5 \%$ in 2007 and $10.3 \%$ in $2009 .{ }^{7}$ In terms of the global trend, Taiwan has now succeeded in raising the proportion of PD usage to the average level within developed countries. ${ }^{8}$

With the increasing usage of PD, the costs of the APD and CAPD modalities have become an important issue. Although there appears to have been very limited analysis of the costs involved in APD and CAPD, two specifically focused studies have revealed that APD has higher medical costs than CAPD, with the greatest differences being the costs of the dialysis machines and disposables. $^{9-11}$ The prior studies have not, however, examined the differences between APD and CAPD in terms of the non-dialysis-related medical utilisation, which may be attributable to complications and clinical outcomes brought about by APD or CAPD; neither did they report differences in the out-of-pocket payment, including expenses on caregivers, as well as productivity losses from patients and family. Therefore, we set out in this study, from a societal perspective, to compare economic costs between APD and CAPD patients in Taiwan using population-based NHI claims data and face-to-face interviews.

\section{METHODS}

\section{Data sources, study design, setting and population}

The joint institutional Review Board of Taipei Medical University approved this study (No. 201503 057). The first part of this study was a nationwide retrospective cohort study covering the years 2004 to 2011 based on the claims data obtained from the National Health Insurance Research Database (NHIRD). Taiwan's mandatory-enrolment, single-payer NHI programme was launched on 1 March 1995, with the programme now covering more than 23 million enrollees, representing over $99 \%$ of the entire population. The NHIRD contains registration files and original claims data for the reimbursement of medical services by enrollees, potentially making it one of the largest and most comprehensive administrative healthcare databases worldwide. The NHIRD has been utilised for previous epidemiologic research, and the results have been validated for HD and PD patients. ${ }^{12}{ }^{13}$ Comprehensive details on the files used from the NHIRD in this study have already been provided in our previous work. ${ }^{14}$ ESRD patients requiring long-term dialysis in Taiwan are identified as patients with a catastrophic illness, as confirmed by two nephrologists, who may then be exempted from co-payments within the NHI system. The cohort of incident patients receiving long-term PD in the present study (new ESRD patients) were identified from the registry for catastrophic illness (International Classification of Diseases, 9th Revision, Clinical Modification, (ICD-9-CM), 585) within the NHIRD. These PD patients were in receipt of long-term PD therapy for at least three consecutive months between 1 January 2006 and 31 December 2010. Clinical characteristics were collected on the sample patients, with these patients subsequently being followed-up by referring to the NHIRD database covering the period from 1 January 2004 to 31 December 2011. We further categorised the patients into two types, APD or CAPD, according to whether they were receiving PD via a cycler for at least 90 days after the initiation of PD. A total of 1801 patients receiving APD therapy, and 4205 patients receiving CAPD therapy, were included in this study. A schematic illustration of the inclusion and exclusion criteria of the study sample is provided in figure 1 . The second part of this study was a multicentre study by crosssectional interviews on patients over 18 years old, carried out at the nephrology outpatient clinics of five hospitals located in northern, central, southern and eastern Taiwan from April 2015 to March 2016. The patient interviews were performed face to face by well-trained nurses from the site or graduate students from Taipei Medical University. All the interviewers had attended interviewer training before they performed the interview. In total, there were 117 APD patients and 129 CAPD patients available for analysis.

\section{Outcome measurement}

The NHI-financed medical costs and utilisation during the 5-year period after the index date are the main outcomes of interest in the national cohort study. The 'index date' is defined in this study as the first day on which the corresponding patient started receiving their APD or CAPD therapy for a period of at least 90 days. The patients were then followed-up for a period of up to 5 years until 31 December 2011, when the data were censored, or until the occurrence of: (1) the change from APD to CAPD modality for at least 60 days, or vice versa (to evaluate the pure therapeutic period of APD or CAPD); (2) the change from PD to HD for at least 90 days; (3) the receipt of a kidney transplant; or (4) the death of the patient. The medical costs that had been incurred by each patient were traced back, starting from the index date to the last day of the follow-up period, after which we then calculated the total medical costs classified by the 'outpatient', 'emergency' and 'inpatient' departments. The total medical costs were divided on the basis of whether they were 'dialysisrelated' or 'non-dialysis related'. The 'dialysis-related' costs were defined as: (1) costs of the APD machine and set; (2) costs of erythropoietin and PD solution; (3) administration, physician and nursing fee; and (4) intubation and extubation cost of the PD catheter. The total 
Figure 1 Study sample selection process. Automated peritoneal dialysis (APD) or continuous ambulatory peritoneal dialysis (CAPD) patients were further categorised according to whether they were receiving peritoneal dialysis (PD) via a cycler for at least 90 days after the initiation of PD. Clinical characteristics of the national cohort study were collected and followed-up covering the period from 2004 to 2011.

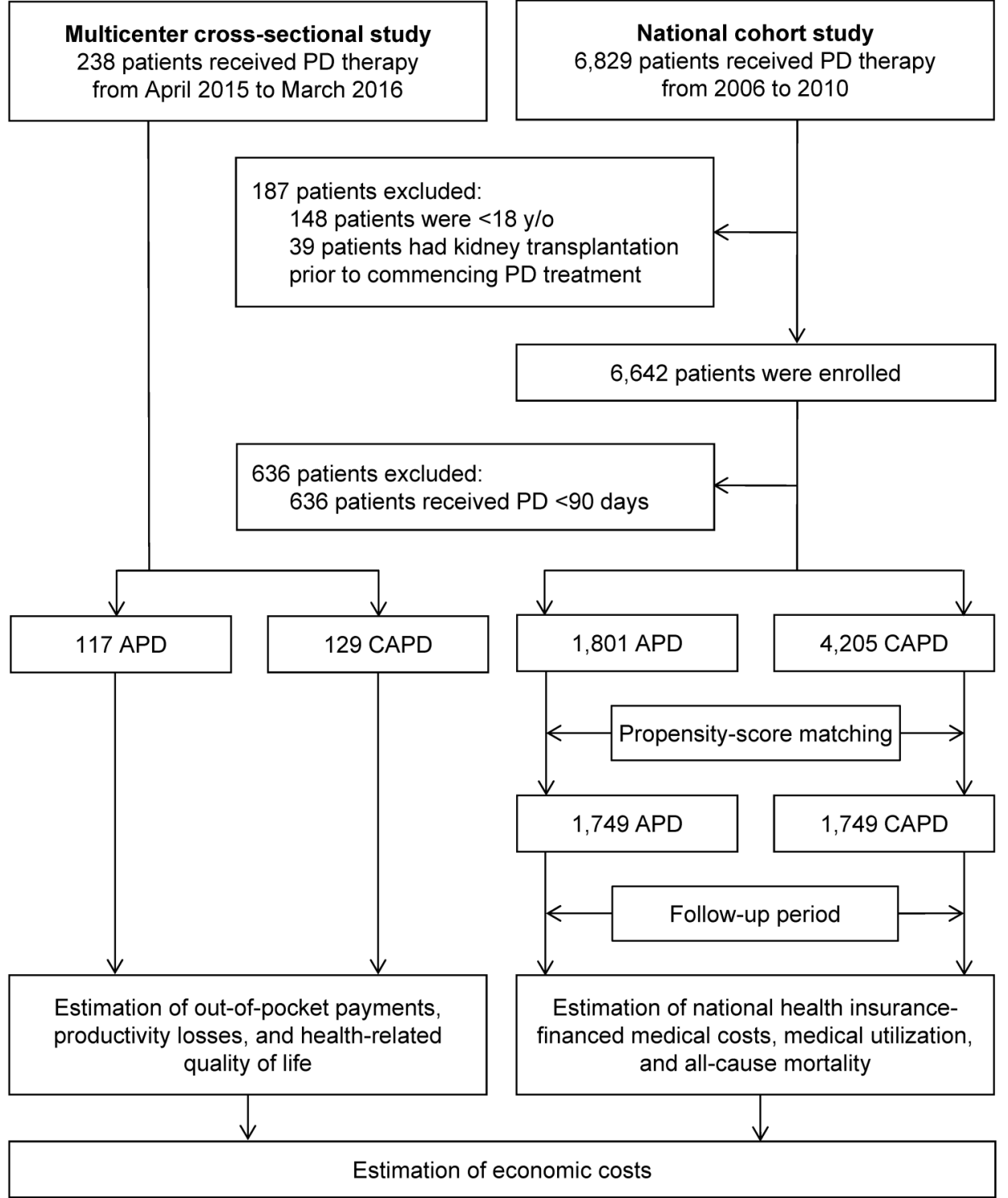

medical utilisation was subsequently calculated from the index date to the last day of the follow-up period, with all utilisation being classified by specific departments. The total medical costs and number of medical visits per patient-year were defined as the total medical costs and number of medical visits within the follow-up period divided by the number of days in the same period. There were no differences in terms of administration, physician and nursing fees between the APD and CAPD patients. There were also no regional differences in the amount reimbursed for medical services in Taiwan.

The secondary outcomes examined the differences in out-of-pocket payments, productivity losses and health-related quality of life (QoL) between APD and CAPD patients. There were two sources of time loss evaluated: patients' and caregivers' time spent in seeking care, and time spent in operating dialysis apparatus at home. Productivity losses were valued using the 'human capital-cost approach', ${ }^{15}$ and were measured by multiplying the loss of time in hours or days with average hourly/daily wage rate reported by the DirectorateGeneral of Budget, Accounting, and Statistics, Taiwan (see online supplementary table S1). Out-of-pocket payments included all expenses related to ESRD paid by the patient/family and not reimbursed by the NHI, such as expenses for medicines, medical materials and devices, herbal and complementary medicines, and nutritional supplements. QoL was elicited using the visual analogue scale, and the EuroQol-5D-5L (EQ-5D-5L) with five levels of severity. The EQ-5D-5L index score was calculated based on a scoring algorithm representing the preferences of Japanese residents because there is no population-based preference weight available in Taiwan. ${ }^{16}$

\section{Statistical analysis}

A logistic regression analysis was carried out on the APD versus CAPD patients using the variables listed in online supplementary table S2. We then used the propensity score analysis to match the APD patients with the CAPD 
patients. ${ }^{17}$ Further analyses began with a comparison of those patients who were in receipt of either the APD or CAPD therapy at the baseline. Second, an independent paired t-test was then carried out to analyse the normally-distributed continuous variables, as well as a Wilcoxon rank sum test to analyse the non-normally distributed continuous variables by their median level. In addition, $\chi^{2}$ tests were carried out on the categorical variables. Third, the log-rank test and the Kaplan-Meier method were used to examine the mortality and chart the survival curves. Then a Cox proportional hazard regression was performed to examine the differences in patient survival. Fourth, in analysing the patient interview survey data, the Mann-Whitney $U$ test and Wilcoxon rank sum test were performed to assess the differences between the APD and CAPD patients. Finally, a bootstrap analysis was further performed on NHI-financed medical costs, as well as on out-of-pocket payments and productivity losses, by forming 1000 bootstrap samples of APD and CAPD patients of equal size (1749 vs 1749 the in national cohort study, and 117 vs 129 in the patient interview survey) with replacement. The difference between the groups was considered to be significant if the two-sided $\mathrm{p}$ value was $<0.05$. All of the analyses in this study were undertaken using the SAS 9.3 software (SAS Institute, Cary, North Carolina, USA).

Additionally, the PD patients, who have a catastrophic illness, may receive lower wage rates than the general population, resulting in lower productivity losses. In order to assess the impact of productivity losses on the total economic costs, we adjusted the productivity losses for the mean Taiwan unemployment rate during the interview period ${ }^{18}$ and then set the productivity losses with a $20 \%, 30 \%$ or $40 \%$ decrement of wages as different scenarios to calculate the total economic costs.

\section{RESULTS}

\section{Demographic characteristics}

Figure 1 shows the study sample selection process. A total of 1749 APD patients and 1749 CAPD patients were enrolled in the national cohort study, and a total of 117 APD patients and 129 CAPD patients were interviewed in the multicentre cross-sectional study. Demographic characteristics are shown in online supplementary tables S2 and S3. There were 265 patients who were put on HD (15.2\%) among the APD patients during the 45192 patient-months of follow-up. The result was greater than the 206 patients $(11.8 \%)$ among the CAPD patients during the 47272 patient-months of follow-up (APD: 70.4 per 1000 patient-years, CAPD: 52.3 per 1000 patient-years; $\mathrm{p}<0.01)$. There were 324 deaths $(18.5 \%)$ among the APD patients during the 45192 patientmonths of follow-up. This was greater than the 311 deaths $(17.8 \%)$ among the CAPD patients during the 47272 patient-months of follow-up (APD: 86.0 per 1000 patient-years, CAPD: 78.9 per 1000 patient-years; $\mathrm{p}=0.22)$. The survival rates at 60 months for the APD and CAPD patients were $61.5 \%$ and $62.3 \%$, respectively (see online supplementary figure $\mathrm{S} 1$ ). The result of Cox proportional hazard regression showed the APD and CAPD patients had a similar risk of death after adjusting for age, Charlson comorbidity index score, diabetes and cardiovascular diseases $(\mathrm{p}=0.13)$.

\section{The NHI-financed medical costs and utilisation}

The NHI-financed medical costs per patient-year for both the APD and CAPD patients are reported in table 1 . The median total medical costs were found to be US $\$ 3769$ higher among the APD patients than the CAPD patients (US\$23005 vs US $\$ 19237, \mathrm{p}<0.01$ ). Following further classification of the medical costs based on the various departments, the APD patients were found to have significantly higher median costs than the CAPD patients in both the outpatient care (US $\$ 20158$ vs US $\$ 16883, \mathrm{p}<0.01)$ and the inpatient care (US $\$ 1197$ vs US $\$ 992, p=0.01$ ). If classified based on dialysis-related or non-dialysis-related costs, the APD patients had higher median costs than the CAPD patients (US $\$ 19235$ vs US $\$ 16050, \mathrm{p}<0.01$ ), with the largest difference between the two groups being in the outpatient care (US\$18 579 vs US $\$ 15594, \quad \mathrm{p}<0.01$ ). Non-dialysis-related medical costs were also found to be higher among the APD patients than the CAPD patients (US\$2975 vs US $\$ 2639, \mathrm{p}<0.01$ ), with the largest difference between the two groups being in the inpatient care (US $\$ 1007$ vs US $\$ 863, p=0.03$ ). In the bootstrap analysis, the mean total medical costs were found to be US $\$ 3589$ higher among the APD patients than the CAPD patients (US\$23 488 vs US $\$ 19899$, $\mathrm{p}<0.001$ ).

Expenditure on the PD solution was found to be the highest cost item among all of the categories in both patient groups. Although the PD solution costs of the APD patients were significantly lower than those of the CAPD patients (US $\$ 9762$ vs US $\$ 10107, \mathrm{p}<0.01$ ), the APD patients were found to require significantly higher quantities of the PD solution than the CAPD patients (3700 L vs $2706 \mathrm{~L}, \mathrm{p}<0.01)$.

The greatest differences in the dialysis-related costs were found to be the costs of the APD machines (US $\$ 795$ vs US $\$ 0, p<0.01$ ), and those of the APD sets (US $\$ 2913$ vs US $\$ 0, p<0.01)$. No discernible differences were found in the costs and the defined daily dosage (DDD) of erythropoietin between the APD and CAPD patients.

The annual NHI-financed medical utilisation rates for both the APD and CAPD patients are reported in table 2, whereas no differences were found in the all items between the two patient groups.

\section{Multicentre cross-sectional study for out-of-pocket payments and productivity losses}

Results of the out-of-pocket payment, productivity losses and QoL are reported in table 3. There were no discernable differences between the APD and CAPD patients in the out-of-pocket payments (US\$1075 vs US $\$ 855$, $\mathrm{p}=0.62$ ), although the APD patients had significantly 
Table 1 NHI-financed medical costs per patient-year for PD patients

\begin{tabular}{|c|c|c|c|c|c|c|c|c|}
\hline \multirow[b]{2}{*}{ Variables } & \multicolumn{3}{|c|}{ APD $(n=1749)$} & \multicolumn{3}{|c|}{ CAPD (n=1749) } & \multirow{2}{*}{$\begin{array}{l}\text { Median } \\
\text { difference }\end{array}$} & \multirow[b]{2}{*}{ p Value } \\
\hline & Mean & Median & SD & Mean & Median & SD & & \\
\hline Total medical costs (US $\$)^{\star}$ & 25498 & 23005 & 10646 & 21879 & 19237 & 16635 & 3769 & $<0.01$ \\
\hline \multicolumn{9}{|l|}{ Classified by departments } \\
\hline Outpatient department & 20010 & 20158 & 3607 & 16918 & 16883 & 7419 & 3275 & $<0.01$ \\
\hline Emergency department & 263 & 100 & 524 & 237 & 85 & 470 & 15 & 0.14 \\
\hline Inpatient department & 5225 & 1197 & 10766 & 4724 & 992 & 12423 & 206 & 0.01 \\
\hline \multicolumn{9}{|c|}{ Classified by non-dialysis or dialysis } \\
\hline Non-dialysis-related & 6296 & 2975 & 9703 & 5964 & 2639 & 16013 & 336 & $<0.01$ \\
\hline Outpatient department & 1574 & 1258 & 1505 & 1595 & 1207 & 6900 & 51 & $<0.01$ \\
\hline Emergency department & 256 & 99 & 510 & 232 & 84 & 463 & 14 & 0.15 \\
\hline Inpatient department & 4466 & 1007 & 9338 & 4137 & 863 & 11210 & 144 & 0.03 \\
\hline Dialysis-related (by department) & 19202 & 19235 & 3340 & 15914 & 16050 & 2917 & 3185 & $<0.01$ \\
\hline Outpatient department & 18436 & 18579 & 3344 & 15323 & 15594 & 2885 & 2985 & $<0.01$ \\
\hline Emergency department & 7 & 0 & 43 & 4 & 0 & 26 & 0 & 0.04 \\
\hline Inpatient department & 759 & 91 & 1720 & 587 & 41 & 1610 & 51 & $<0.01$ \\
\hline Dialysis-related (by items) & 19202 & 19235 & 3340 & 15914 & 16050 & 2917 & 3185 & $<0.01$ \\
\hline APD set & 2391 & 2913 & 1089 & 48 & 0 & 213 & 2913 & $<0.01$ \\
\hline APD machine & 813 & 795 & 208 & 16 & 0 & 61 & 795 & $<0.01$ \\
\hline Cost of erythropoietin & 1622 & 1763 & 654 & 1618 & 1736 & 620 & 27 & 0.80 \\
\hline PD-related costs $†$ & 3390 & 3466 & 416 & 3407 & 3470 & 409 & -4 & 0.02 \\
\hline PD solution & 9609 & 9762 & 2464 & 9887 & 10107 & 2178 & -346 & $<0.01$ \\
\hline Others & 1377 & 811 & 1873 & 938 & 503 & 1627 & 308 & $<0.01$ \\
\hline \multicolumn{9}{|l|}{ Dialysis-related (by quantities) } \\
\hline Quantity of PD solution (L) & 3653 & 3700 & 740 & 2651 & 2706 & 629 & 994 & $<0.01$ \\
\hline PRBC transfusion (unit) & 3.7 & 0 & 13.5 & 3.3 & 0 & 8.7 & 0 & 0.15 \\
\hline Oral iron supply (mg) & 2956 & 0 & 10357 & 2155 & 0 & 8787 & 0 & 0.40 \\
\hline Erythropoietin (DDD) $\ddagger$ & 145.2 & 5.1 & 86.2 & 145.1 & 5.2 & 85.5 & 0 & 0.96 \\
\hline Extubation of PD catheter & 0.06 & 0 & 0.29 & 0.05 & 0 & 0.24 & 0 & 0.35 \\
\hline \multicolumn{9}{|l|}{ After bootstrap analysis } \\
\hline Total medical costs (US\$)* & 23488 & & 783 & 19899 & & 173 & & $<0.001$ \\
\hline Non-dialysis-related & 4723 & & 629 & 4340 & & 168 & & $<0.001$ \\
\hline Dialysis-related & 18859 & & 157 & 15768 & & 76 & & $<0.001$ \\
\hline
\end{tabular}

*US $\$ 1=30$ New Taiwan Dollars.

†Costs include: (1) administration, physician and nursing fee; and (2) intubation and extubation cost of peritoneal dialysis catheter. $\ddagger 1 \mathrm{DDD}=1000 \mathrm{IU}$ epoetin alfa $=1000 \mathrm{IU}$ epoetin beta $=5 \mu \mathrm{g}$ darbepoetin alfa $=4 \mu \mathrm{g}$ methoxy polyethylene glycol-epoetin beta.

APD, automated peritoneal dialysis; CAPD, continuous ambulatory peritoneal dialysis; DDD, defined daily dose; NHI, National Health Insurance; PD, peritoneal dialysis; PRBC, packed red blood cell.

Table 2 Annual NHI-financed medical utilisation per patient-year of peritoneal dialysis patients

\begin{tabular}{|c|c|c|c|c|c|c|c|c|}
\hline \multirow[b]{2}{*}{ Variables } & \multicolumn{3}{|c|}{ APD $(n=1749)$} & \multicolumn{3}{|c|}{ CAPD $(n=1749)$} & \multirow{2}{*}{$\begin{array}{l}\text { Median } \\
\text { difference }\end{array}$} & \multirow[b]{2}{*}{ p Value } \\
\hline & Mean & Median & SD & Mean & Median & SD & & \\
\hline Total no. of visits/hospitalisations & 44.58 & 40.63 & 18.86 & 44.51 & 40.50 & 20.09 & 0.13 & 0.53 \\
\hline \multicolumn{9}{|l|}{ Visits classified by department } \\
\hline Outpatient visits & 41.56 & 38.13 & 17.77 & 41.59 & 37.89 & 18.90 & 0.24 & 0.68 \\
\hline Dialysis-related visits & 14.35 & 12.43 & 4.39 & 13.49 & 12.40 & 3.48 & 0.03 & 0.24 \\
\hline Non-dialysis-related visits & 27.22 & 23.73 & 17.54 & 28.11 & 24.38 & 18.67 & -0.65 & 0.25 \\
\hline Emergency room visits & 1.66 & 0.90 & 2.47 & 1.60 & 0.87 & 2.33 & 0.04 & 0.51 \\
\hline Hospitalisations & 1.36 & 0.79 & 1.69 & 1.31 & 0.76 & 1.75 & 0.03 & 0.23 \\
\hline
\end{tabular}

higher co-payment for outpatient visits than the CAPD patients (US $\$ 60$ vs US $\$ 48, p=0.03$ ). Compared with the CAPD patients, the APD patients had lower annual productivity losses (US $\$ 2619$ vs US $\$ 6443, \mathrm{p}<0.001$ ), resulting from less time spent seeking care (APD, 45.0 hours vs
CAPD, 59.9 hours, $\mathrm{p}<0.001$ ), and less time spent operating dialysis apparatus (APD, 330.4 hours vs CAPD, 821.3 hours, $\mathrm{p}<0.001)$. In terms of QoL, there were no significant differences between the APD and CAPD patients in each dimension of EQ-5D-5L. Details of EQ-5D-5L by 
Table 3 Per patient-year out-of-pocket payments and productivity losses as well as quality of life by interview survey of peritoneal dialysis patients

\begin{tabular}{|c|c|c|c|c|c|c|c|c|c|c|}
\hline \multirow[b]{2}{*}{ Variables } & \multicolumn{4}{|c|}{ APD $(n=117)$} & \multicolumn{4}{|c|}{ CAPD $(n=129)$} & \multirow[b]{2}{*}{$\begin{array}{l}\text { Median } \\
\text { difference }\end{array}$} & \multirow[b]{2}{*}{ p Value } \\
\hline & Mean & Median & SD & $\begin{array}{l}\text { Reporting moderate to } \\
\text { extreme problems (\%) }\end{array}$ & Mean & Median & SD & $\begin{array}{l}\text { Reporting moderate to } \\
\text { extreme problems (\%) }\end{array}$ & & \\
\hline Out-of-pocket payments (US\$) & 2012 & 1075 & 2861 & & 2170 & 855 & 3182 & & 220 & 0.62 \\
\hline Co-payment to outpatient visits & 165 & 60 & 283 & & 126 & 48 & 274 & & 12 & 0.03 \\
\hline Co-payment to hospitalisations & 417 & 0 & 920 & & 381 & 0 & 816 & & 0 & 0.66 \\
\hline Medicine not covered by $\mathrm{NHI}$ & 424 & 67 & 861 & & 374 & 0 & 667 & & 67 & 0.22 \\
\hline Medical equipment & 188 & 120 & 265 & & 165 & 67 & 312 & & 53 & 0.19 \\
\hline Chinese medication & 149 & 0 & 1247 & & 4 & 0 & 25 & & 0 & 0.12 \\
\hline Traditional medicine & 36 & 0 & 311 & & 6 & 0 & 70 & & 0 & 0.02 \\
\hline Nutritional supplements & 184 & 0 & 561 & & 246 & 0 & 1214 & & 0 & 0.52 \\
\hline Caregiver costs & 381 & 0 & 1697 & & 783 & 0 & 2438 & & 0 & 0.35 \\
\hline Transportation costs & 68 & 39 & 94 & & 84 & 58 & 89 & & -19 & 0.12 \\
\hline \multicolumn{11}{|l|}{ Seeking outpatient care } \\
\hline From patients & 274 & 214 & 211 & & 341 & 333 & 254 & & -118 & 0.04 \\
\hline From family caregivers & 125 & 0 & 235 & & 192 & 0 & 352 & & 0 & 0.19 \\
\hline \multicolumn{11}{|l|}{ Seeking inpatient care } \\
\hline From patients & 402 & 0 & 600 & & 426 & 0 & 588 & & 0 & 0.75 \\
\hline From family caregivers & 254 & 0 & 489 & & 334 & 0 & 539 & & 0 & 0.16 \\
\hline $\begin{array}{l}\text { Time spent operating dialysis } \\
\text { apparatus }\end{array}$ & 1952 & 2020 & 1626 & & 4831 & 5059 & 2780 & & -3039 & $<0.001$ \\
\hline Visual analogue scale & 72.8 & 75.0 & 15.6 & - & 69.0 & 70.0 & 17.9 & - & & 0.05 \\
\hline $\begin{array}{l}\text { Utility from EuroQol-5D-5L } \\
\text { index } \dagger\end{array}$ & 0.82 & 0.87 & 0.19 & & 0.82 & 0.87 & 0.21 & & & 0.68 \\
\hline Mobility & - & - & - & 7.7 & - & - & - & 13.2 & & 0.16 \\
\hline Self-care & - & - & - & 9.4 & - & - & - & 9.3 & & 0.98 \\
\hline Usual activities & - & - & - & 7.7 & - & - & - & 13.2 & & 0.16 \\
\hline Pain/discomfort & - & - & - & 12.8 & - & - & - & 16.3 & & 0.44 \\
\hline Anxiety/depression & - & - & - & 11.1 & - & - & - & 14.7 & & 0.40 \\
\hline \multicolumn{11}{|l|}{ After bootstrap analysis } \\
\hline Out-of-pocket payments (US\$) & 2019 & & 261 & & 2171 & & 272 & & & $<0.001$ \\
\hline Productivity losses (US\$) & 3007 & & 200 & & 6125 & & 285 & & & $<0.001$ \\
\hline EuroQol-5D-5L index & 0.82 & & 0.02 & & 0.82 & & 0.02 & & & 0.52 \\
\hline
\end{tabular}


five severity levels are shown in online supplementary table S4. The results of the mean out-of-pocket payments, productivity losses and EQ-5D-5L index remained unchanged in the bootstrap analysis.

\section{Economic costs}

The total economic costs per patient-year, including the direct medical costs by NHI, out-of-pocket payments and productivity losses, are reported in table 4. NHI-financed medical costs comprised of a higher proportion of the total economic costs among the APD patients than those of the CAPD patients; in contrast, productivity losses contributed to a higher proportion of the total economic costs among the CAPD patients than among the APD patients. The total economic costs of APD (US\$30 401) were similar to those of CAPD (US \$29 939), even after bootstrap analysis (APD, US\$28 399; CAPD, US $\$ 27960$ ). After considering the productivity losses under various scenarios, the differences in total economic costs between the APD and CAPD patients slightly increased in models $2-4$.

\section{DISCUSSION}

The main results of this study using Taiwan's populationbased claims data and interview survey data demonstrate that total economic costs of APD (US\$29 977) were close to the costs of CAPD (US\$30 750). The annual medical costs for the APD patients were US $\$ 3769$ higher than those of the CAPD patients, with the greatest difference (US\$2985) being found in the costs of outpatient care for dialysis, accounting for $80 \%$ of the difference in the total costs. The main source of the differences between the APD patients and CAPD patients in terms of dialysis-related costs were those of the APD machines and APD sets. As regards the medical utilisation rates, no significant differences were discernible between the APD and CAPD patients. The results from the interview survey demonstrated lower productivity losses in the APD patients than the CAPD patients, but no differences were detected in the out-of-pocket payments among the two patient groups. The differences in direct medical costs paid by NHI and productivity losses between APD and CAPD remained robust in the bootstrap analysis.

The NHI-financed medical utilisation between the APD and CAPD patients are quite similar; however, a significantly higher total of the NHI-financed medical costs were discernible among the APD patients than among the CAPD patients. This would seem to indicate that the costs per outpatient or emergency room visit are higher among the APD patients. Furthermore, while the APD patients were found to have similar numbers of hospitalisation to the CAPD patients (0.79 vs $0.76, \mathrm{p}=0.23)$, the APD patients were found to have higher inpatient costs

Table 4 Total economic costs per patient-year of APD and CAPD patients

\begin{tabular}{|c|c|c|}
\hline Variables & APD & CAPD \\
\hline Direct medical costs by $\mathrm{NHI}(\mathrm{US} \$)^{\star}$ & 25498 & 21879 \\
\hline Out-of-pocket payments (US\$) & 2012 & 2170 \\
\hline Productivity losses (US\$) & 3006 & 6125 \\
\hline Adjusted for unemployment rate $†$ & 2891 & 5890 \\
\hline Adjusted for unemployment rate and a $20 \%$ decrement in wages & 2312 & 4712 \\
\hline Adjusted for unemployment rate and a $30 \%$ decrement in wages & 2023 & 4123 \\
\hline Adjusted for unemployment rate and a $40 \%$ decrement in wages & 1734 & 3534 \\
\hline Total costs, model $1 \ddagger$ & 30401 & 29939 \\
\hline Total costs, model $2 \ddagger$ & 29822 & 28761 \\
\hline Total costs, model 3ł & 29533 & 28172 \\
\hline Total costs, model $4 \ddagger$ & 29244 & 27583 \\
\hline \multicolumn{3}{|l|}{ After bootstrap analysis } \\
\hline Direct medical costs by NHI (US\$) & 23488 & 19899 \\
\hline Out-of-pocket payments (US\$) & 2019 & 2171 \\
\hline Productivity losses (US\$) & 3007 & 6125 \\
\hline Adjusted for unemployment rate† & 2892 & 5890 \\
\hline Adjusted for unemployment rate and a $20 \%$ decrement in wages & 2313 & 4712 \\
\hline Adjusted for unemployment rate and a $30 \%$ decrement in wages & 2024 & 4123 \\
\hline Adjusted for unemployment rate and a $40 \%$ decrement in wages & 1735 & 3534 \\
\hline Total costs, model $1 \ddagger$ & 28399 & 27960 \\
\hline Total costs, model $2 \ddagger$ & 27820 & 26782 \\
\hline Total costs, model $3 \ddagger$ & 27531 & 26193 \\
\hline Total costs, model $4 \ddagger$ & 27242 & 25604 \\
\hline \multicolumn{3}{|c|}{$\begin{array}{l}\text { *US } \$ 1=30 \text { New Taiwan Dollars. } \\
\text { †Adjusted for mean Taiwan unemployment rate }(3.82 \%) \text { between April } 2015 \text { and March } 2016 . \\
\text { †Models } 1-4 \text { : Total costs include direct medical costs financed by NHI, out-of-pocket payments, and productivity losses adjusted for } \\
\text { unemployment rate (model } 1 \text { ); adjusted for unemployment rate and a } 20 \% \text { decrement in wages (model } 2 \text { ); adjusted for unemployment rate } \\
\text { and a } 30 \% \text { decrement in wages (model } 3 \text { ); adjusted for unemployment rate and a } 40 \% \text { decrement in wages (model } 4 \text { ). } \\
\text { APD, automated peritoneal dialysis; CAPD, continuous ambulatory peritoneal dialysis; NHI, National Health Insurance. }\end{array}$} \\
\hline
\end{tabular}


than the CAPD patients, particularly those relating to non-dialysis inpatient treatment. This would seem to indicate that the costs per hospitalisation are again higher or the hospital stays are longer among the APD patients than the CAPD patients, possibly owing to the higher incident rate of patients changed to HD among the APD patients (APD: 70.4 per 1000 patient-years, CAPD: 52.3 per 1000 patient-years; $\mathrm{p}<0.01$ ).

The NHI-financed dialysis-related costs of the APD patients are approximately 1.2 times higher than those of the CAPD patients, which is in line with the results of several related studies carried out in other countries. $^{9}{ }^{19-21}$ The major sources of the higher dialysis-related costs for the APD patients were found to be the APD machines (4.2\%), APD sets and PD solution $(62.5 \%)$, and erythropoietin $(8.4 \%)$, while those for the CAPD patients were PD solution $(62.4 \%)$ and erythropoietin $(10.2 \%)$. The differences between the dialysisrelated costs for the APD patients and the CAPD patients were mainly attributable to the costs of the APD machines and APD sets (table 1). These costs were US $\$ 3708$ higher among the APD patients than the CAPD patients. When compared to CAPD, APD involves the use of a cycler and extra line sets, which explains the higher dialysis costs involved in the APD treatment. The results of a related UK study also indicated that the greatest differences in costs between APD and CAPD were attributable to the APD machines and disposables. ${ }^{9}$ In addition, APD patients had the lower costs and higher quantities of PD solutions. The most likely reasons were that the per-litre cost of the commonly used $5 \mathrm{~L}$ bag PD solution for APD is much cheaper than that of the commonly used $2 \mathrm{~L}$ bag PD solution for CAPD, and that the APD patients usually received shorter dwell time but more exchanges than the CAPD patients to reach adequate dialysis. ${ }^{22}$

The present study features an overall evaluation of the costs associated with patients undergoing APD and CAPD, with out-of-pocket payments and productivity losses incorporated into the analysis, which were rarely assessed in previous studies. From the payer's perspective, the NHI-financed medical costs of the CAPD seems to be a more cost-saving modality than those of the APD; however, from a societal perspective, the annual economic costs of APD were close to those of CAPD although differences exist in the proportion of key cost components. Based on the human capital-cost approach, ${ }^{15}$ the productivity losses were estimated as the reduced future gross income, including reduced paid or unpaid production, due to PD related mortality and/or morbidity and contributed to a lower proportion of the total economic costs for APD rather than that of CAPD. On the other hand, NHI-financed medical costs made up a larger portion of the total economic costs for APD than that of CAPD. This is reflected in the fact that the costs of the productivity losses, resulting from the time spent seeking care and operating dialysis apparatus, were significantly lower in the APD than CAPD patients.
With the help of the APD machine, the APD modality spent less time in operating dialysis so as to decrease the productivity losses; however, it correspondingly increases the costs of the APD machines and APD sets.

The mortality rates of the APD and CAPD patients were similar and the result did not differ from most of the previous findings of multicentre or nationwide cohort studies. ${ }^{13192324}$ In terms of QoL, the results of the visual analogue scale and EQ-5D-5L were quite similar in the APD and CAPD patients (table 3 and online supplementary table S4), which were consistent with the findings published from the literature..$^{25-28}$

The results of the present study also have some limitations. First, the major drawbacks are those commonly found in administrative database research. Although comorbidities and medications were matched at cohort entry, the patient's weight, peritoneal equilibration test and dialysis clearance, and their level of residual renal function are not available from the NHIRD. These unidentified data are potentially confounding factors in the prescriptions of the peritoneal dialysate dose. Other potential confounding factors that are not available from the claims database when computing the propensity scores were patient preference, self-care ability and physician selection. Second, the productivity losses estimated in this study were the value of time lost by patients and their family caregivers when seeking care/ operating dialysis apparatus. Productivity losses related to presentism (impaired productivity or reduced effectiveness at work associated with ESRD) were not included in this study and thus may have led to an underestimation of the economic costs. Finally, the ED-5D-5L index score was calculated based on a scoring algorithm representing the preferences of Japanese residents which may not perfectly represent those of Taiwanese people.

Although NHI-financed annual medical costs of CAPD had a greater reduction in expenses than those of the APD, CAPD had higher annual productivity losses than APD. To extend the generalisability of our findings to other national health systems, our results highlight that the APD modality may appear to be more desirable in terms of its substantially lower productivity losses for countries with a higher value of time (hourly wage or daily wage), or with a younger dialysis patient population.

In this study, we present a national cohort study to analyse NHI-financed medical utilisation and medical costs and a cross-sectional study to survey the out-of-pocket payments and productivity losses for APD and CAPD patients. From a societal perspective, although APD had higher annual dialysis-related costs financed by NHI, the overall economic costs of APD were very close to those of CAPD because CAPD had higher annual productivity losses than APD.

\section{Author affiliations}

${ }^{1}$ School of Health Care Administration, College of Management, Taipei Medical University, Taipei, Taiwan

${ }^{2}$ Institute of Health Policy and Management, College of Public Health, National Taiwan University, Taipei, Taiwan 
${ }^{3}$ Division of Nephrology, Department of Internal Medicine, School of Medicine, College of Medicine, Taipei Medical University, Taipei, Taiwan ${ }^{4}$ Division of Nephrology, Department of Internal Medicine, Taipei Medical University Hospital, Taipei Medical University, Taipei, Taiwan

${ }^{5}$ Division of Nephrology, Department of Internal Medicine, Taichung Veterans General Hospital and Rong Hsing Research Center for Translational Medicine, Institute of Biomedical Science, College of Life Science, National Chung Hsing University, Taichung, Taiwan

${ }^{6}$ Division of Nephrology, Department of Internal Medicine, Buddhist Tzu Chi General Hospital and School of Medicine, Tzu Chi University, Hualien, Taiwan ${ }^{7}$ Department of Internal Medicine, Faculty of Renal Care, Kaohsiung Medical University Hospital and, College of Medicine, Kaohsiung Medical University, Kaohsiung, Taiwan

${ }^{8}$ Division of Nephrology, Department of Internal Medicine, Wan Fang Hospital, Taipei Medical University, Taipei, Taiwan

Contributors Obtained funding: SYM and TCH. SYM and TCH take responsibility for the integrity of the data and the accuracy of the data analysis. Study concept and questionnaire design: SYM, TCH, WYT, HSY, CHH, WMJ, HBG, TJC, and CTH. Acquisition of data: SYM, TCH, WYT, HSY, CHH, WMJ, HBG, TJC, and CTH. Analysis and interpretation of data: SYM, TCH, WYT, HSY, $\mathrm{CHH}, \mathrm{WMJ}, \mathrm{HBG}$, TJC, and CTH. Statistical analysis: SYM, TCH, WYT, and HSY All authors participated in writing the paper, reviewed it for important intellectual content and approved the final version. Final approval of the manuscript: SYM, TCH, WYT, HSY, CHH, WMJ, HBG, TJC, and CTH.

Funding This research received grants from National Science Council (NSC 102-2815-C-038-007-H) and from Wan Fang Hospital, Taipei Medical University, Taiwan (102TMU-WFH-08 and 104TMU-WFH-12).

Competing interests None declared.

Patient consent Obtained.

Ethics approval The Joint Institutional Review Board of Taipei Medical University.

Provenance and peer review Not commissioned; externally peer reviewed.

Data sharing statement No additional data are available.

Open Access This is an Open Access article distributed in accordance with the Creative Commons Attribution Non Commercial (CC BY-NC 4.0) license, which permits others to distribute, remix, adapt, build upon this work noncommercially, and license their derivative works on different terms, provided the original work is properly cited and the use is non-commercial. See: http:// creativecommons.org/licenses/by-nc/4.0/

\section{REFERENCES}

1. Yang WC, Hwang SJ. Incidence, prevalence and mortality trends of dialysis end-stage renal disease in Taiwan from 1990 to 2001: the impact of national health insurance. Nephrol Dial Transplant 2008;23:3977-82.

2. National Health Insurance Administration, Ministry of Health and Welfare. http://www.nhi.gov.tw/webdata/webdata.aspx? menu=17\&menu id=662\&webdata id=805\&WD ID=698 (accessed 15 Jun 2015)

3. Mehrotra R, Chiu YW, Kalantar-Zadeh K, et al. Similar outcomes with hemodialysis and peritoneal dialysis in patients with end-stage renal disease. Arch Intern Med 2011;171:110-18.

4. Chang YK, Hsu CC, Hwang SJ, et al. A comparative assessment of survival between propensity score-matched patients with peritoneal dialysis and hemodialysis in Taiwan. Medicine (Baltimore) 2012;91:144-51.

5. Karopadi AN, Mason G, Rettore E, et al. The role of economies of scale in the cost of dialysis across the world: a macroeconomic perspective. Nephrol Dial Transplant 2014;29:885-92.
6. Kao TW, Chang YY, Chen PC, et al. Lifetime costs for peritoneal dialysis and hemodialysis in patients in Taiwan. Perit Dial Int 2013;33:671-8.

7. Wu MS, Wu IW, Shih CP, et al. Establishing a platform for battling end-stage renal disease and continuing quality improvement in dialysis therapy in Taiwan--Taiwan Renal Registry Data System (TWRDS). Acta Nephrologica 2011;25:148-53.

8. Jain AK, Blake P, Cordy P, et al. Global trends in rates of peritoneal dialysis. J Am Soc Nephrol 2012;23:533-44.

9. Baboolal K, McEwan P, Sondhi S, et al. The cost of renal dialysis in a UK setting--a multicentre study. Nephrol Dial Transplant 2008;23:1982-9.

10. Cortes-Sanabria L, Rodriguez-Arreola BE, Ortiz-Juarez VR, et al. Comparison of direct medical costs between automated and continuous ambulatory peritoneal dialysis. Perit Dial Int 2013;33:679-86.

11. Cortes-Sanabria L, Paredes-Cesena CA, Herrera-Llamas RM, et al. Comparison of cost-utility between automated peritoneal dialysis and continuous ambulatory peritoneal dialysis. Arch Med Res 2013;44:655-61.

12. Tang $\mathrm{CH}$, Wang $\mathrm{CC}$, Chen $\mathrm{TH}$, et al. Prognostic benefits of carvedilol, bisoprolol, and metoprolol controlled release/extended release in hemodialysis patients with heart failure: a 10-year cohort. J Am Heart Assoc 2016;5:pii: e002584.

13. Tang $\mathrm{CH}$, Chen TH, Fang TC, et al. Do automated peritoneal dialysis and continuous ambulatory peritoneal dialysis have the same clinical outcomes? A ten-year cohort study in Taiwan. Sci Rep 2016;6:29276.

14. Tang $\mathrm{CH}$, Chen $\mathrm{TH}$, Wang $\mathrm{CC}$, et al. Renin-angiotensin system blockade in heart failure patients on long-term haemodialysis in Taiwan. Eur J Heart Fail 2013;15:1194-202.

15. Liljas B. How to calculate indirect costs in economic evaluations. Pharmacoeconomics 1998;13(1 Pt 1):1-7

16. Shiroiwa $T$, Ikeda $S$, Noto $S$, et al. Comparison of value set based on DCE and/or TTO Data: scoring for EQ-5D-5L health states in Japan. Value Health 2016;19:648-54.

17. D'Agostino RB Jr. Propensity score methods for bias reduction in the comparison of a treatment to a non-randomized control group. Stat Med 1998;17:2265-81.

18. Unemployment rate. National Statistics, R.O.C. (Taiwan). 2016. https://www.stat.gov.tw/point.asp?index=3 (accessed $31 \mathrm{Dec}$ 2016).

19. Badve SV, Hawley CM, McDonald SP, et al. Automated and continuous ambulatory peritoneal dialysis have similar outcomes. Kidney Int 2008;73:480-8.

20. Peeters P, Rublee D, Just PM, et al. Analysis and interpretation of cost data in dialysis: review of Western European literature. Health Policy 2000;54:209-27.

21. De Vecchi AF, Dratwa M, Wiedemann ME. Healthcare systems and end-stage renal disease (ESRD) therapies--an international review: costs and reimbursement/funding of ESRD therapies. Nephrol Dial Transplant 1999;14(Suppl 6):31-41.

22. Akonur A, Firanek CA, Gellens ME, et al. Volume-based peritonea dialysis prescription guide to achieve adequacy targets. Perit Dial Int 2016;36:188-95.

23. Mehrotra R, Chiu YW, Kalantar-Zadeh K, et al. The outcomes of continuous ambulatory and automated peritoneal dialysis are similar. Kidney Int 2009;76:97-107.

24. Michels WM, Verduijn M, Boeschoten EW, et al. Similar survival on automated peritoneal dialysis and continuous ambulatory peritoneal dialysis in a large prospective cohort. Clin J Am Soc Nephrol 2009;4:943-9.

25. Guney I, Solak $\mathrm{Y}$, Atalay $\mathrm{H}$, et al. Comparison of effects of automated peritoneal dialysis and continuous ambulatory peritoneal dialysis on health-related quality of life, sleep quality, and depression. Hemodial Int 2010;14:515-22.

26. Michels WM, van Dijk S, Verduijn M, et al. Quality of life in automated and continuous ambulatory peritoneal dialysis. Perit Dial Int 2011;31:138-47.

27. Balasubramanian G, McKitty K, Fan SL. Comparing automated peritoneal dialysis with continuous ambulatory peritoneal dialysis: survival and quality of life differences? Nephrol Dial Transplant 2011;26:1702-8.

28. Bilgic A, Akman B, Sezer S, et al. Daytime sleepiness and quality of life in peritoneal dialysis patients. Ther Apher Dial 2011;15:565-71. 